\title{
Research on the Upgrading of China's Sports Shoes Manufacturing Enterprise Cluster from the Perspective of Global Value Chain Driving Force
}

\author{
Cong Geng, Teng Fan* \\ Institute of physical education and health, research center for physical education reform and development, \\ College of physical education, Henan University, Kaifeng 475001, Henan, China \\ *Corresponding author.
}

\begin{abstract}
The paper, based on the global value chain theory, this paper studies the sustainable development of China's sports shoes manufacturing industry cluster from the perspective of driving force. First, this paper reviews the relevant theories of global value chain. Then it studies the upgrading mode of sports shoes manufacturing enterprise cluster in China under the theoretical framework of global value chain. After theoretical analysis and empirical study, this paper puts forward the idea of upgrading the sports shoes manufacturing enterprise cluster in China. And finally, corresponding suggestions and countermeasures are put forward to provide a basis for the development of industrial clusters and the formulation of policies from the two dimensions of local and global.
\end{abstract}

Keywords: Global Value Chain; China sports shoes manufacturing enterprise cluster; Driving Force; Development Research

\section{Introduction}

China's sporting goods industry has achieved global admiration in the past three decades. This benefits mainly from reform and opening up, especially after joining the WTO. Driven by reform and opening up dividends, demographic dividends, and resource dividends, the industry has made great progress. However, no dividends can be used unlimitedly. At present, Great changes have taken place in the development environment of the sporting goods industry, especially the three major changes that are hard to avoid. The first is the gradual increase in resource carrying pressure. At present, "money shortage" and "resource shortage" are applying pressure on enterprises from different aspects. The second is the appearance of "Lewis turning point". Since 2010, enterprises in coastal areas of China have encountered the problem of "labor shortage". This year, instead of being alleviated, it has spread to the whole country. Even companies in first-tier cities such as Beijing and Shanghai are also facing difficulties in recruiting workers. The last one is the further slow-down of the export of corporate products and the gradual decrease of product orders.

Therefore, the author believes that facing a shrinking and squeezed dividend space, China's sporting goods industry must carry out industrial structural transformation and industrial upgrading to achieve sustainable development.

\section{The Definition of Global Value Chain}

The United Nations Industrial Development Organization (UNIDO, 2002) pointed out in the Industrial Development Report "Competing Through Innovation and Learning": Global value chain refers to a global cross-enterprise network organization that connects production, sales, recycling and other processes in order to realize the value of goods or services on a global scale. It involves processes from the collection and transportation of raw materials, the production and distribution of semi-finished products and finished products, to the final consumption and recycling. It includes all participants and the organizations of production and sales activities and their value and profit distributions, and supports the capabilities and efficiency of the organization through

ISSN: 0010-8189

(C) CONVERTER 2020 
automated business processes and links with suppliers, partners and customers." [1] This definition emphasizes that the global value chain is not only made up of a large number of complementary enterprises, but also a collection of corporate networks connected through various economic activities. The focus is not only on enterprises, but also on contractual relationships and changing connection ways.

\section{Industrial Upgrading under Global Value Chain}

Industrial economics believes that industrial upgrading refers to the industrial transformation from low-level to high-level, which includes the growth of the total industrial output and the heightened improvement of industrial structure. The four forms of industrial upgrading are: (1) technological process upgrading (2) product upgrading (3) industrial function upgrading (4) value chain upgrading. The general way of upgrading is: from the technological upgrading of original equipment manufacture (OEM) to the product upgrading of original design manufacture (ODM), to the function upgrading of original brand manufacture (OBM), and finally to the upgrading of chain conversion. During the whole upgrading process, the difficulty is getting bigger and bigger, and every upgrading is achieved through competition.

\section{Driving Forces of Industrial Upgrading under Global Value Chain Mode}

Dr. Zhang Shaojun nicely explained the upgrading of the product industry with the business cost theory. Business cost refers to the sum of various expenses that an enterprise spends in the production and operation process. It includes transaction costs and factor costs. The relationship between the two is inversely proportional. Transaction cost mainly refers to [2] industrial supporting environment, marketization degree, infrastructure, government efficiency, etc. that are closely related to the system; factor cost mainly refers to the price level of land, resources, labor and other factors; however, business theory tells us, "Industrial agglomeration can reduce the transaction cost of enterprises' economic activities, but it will cause the increase of local factor costs. When a certain critical value is reached, it will promote the upgrading and transfer of product industries. The dynamic changes of the two will be transformed into the game between centrifugal force and centripetal force and trigger the re-upgrading and configuration of product industries in geographic space.

According to Dr. Zhang's theory, the author believes that the essence of industrial upgrading is that the governors of the value chain use their own advantages to obtain the greatest benefits from the division of labor, and to win higher product added value. This is a vertical fraud against the labor of workers in developing countries and an exploitation chain with strict hierarchical system (first proposed). Although the different links under the global value chain are interrelated, due to the different division of labor, the status and added value of each value chain link have hierarchical differences. They have different factors and returns for different links of labor, capital, etc., which eventually leads to the upgrading of different links in the global value chain, that is, from low value-added links to high value-added links, and from labor-intensive to technology-intensive and knowledge-intensive. The sporting goods industry belongs to the purchaser-driven value chain, in which the design and marketing links are the core links of the value chain and they are located at the two ends of the "smile curve" and belong to the high value-added link. While the manufacturing link located in the middle of the "smile curve" that has relatively low added value and is a labor-intensive industry. Its upgrade manifestation is to upgrade from the manufacturing link to the product research \& development and marketing link.

\section{Current Situation Analysis of Sports Shoe Industry Clusters in China}

\subsection{The Continuous Increase of Factor Cost of Shoe Industry Clusters in China}

As the factor cost situation has a relatively large impact on the development of the clusters, the author has conducted a survey on the factor conditions affecting enterprises. The specific conditions are shown in Table 1.

Table 1 Analysis on Factor Conditions of Clusters

ISSN: 0010-8189

(C) CONVERTER 2020 


\begin{tabular}{llrllll}
\hline & \multicolumn{2}{l}{ Lack of Employees } & \multicolumn{2}{l}{$\begin{array}{l}\text { Lack of Senior Management } \\
\text { Personnel in Enterprises }\end{array}$} & \multicolumn{2}{l}{$\begin{array}{l}\text { Changes in Productive Raw } \\
\text { Materials }\end{array}$} \\
& $\begin{array}{l}\text { Number of } \\
\text { Enterprises }\end{array}$ & $\begin{array}{r}\text { Sample } \\
\text { ratio } \%\end{array}$ & $\begin{array}{l}\text { Number of } \\
\text { Enterprises }\end{array}$ & $\begin{array}{l}\text { Sample } \\
\text { ratio } \%\end{array}$ & $\begin{array}{l}\text { Number of } \\
\text { Enterprises }\end{array}$ & $\begin{array}{l}\text { Sample } \\
\text { ratio \% }\end{array}$ \\
\hline $\begin{array}{l}\text { No Shortage } \\
\text { (no price increase) }\end{array}$ & 4 & 5.9 & 12 & 17.6 & & 2 \\
$\begin{array}{l}\text { Shortage } \\
\text { (Large increase) }\end{array}$ & 28 & 41.2 & 23 & 33.8 & 32 & 46 \\
$\begin{array}{l}\text { Great Shortage } \\
\text { (Huge increase) }\end{array}$ & 36 & 52.9 & 33 & 48.5 & 36 & 52 \\
\hline
\end{tabular}

As shown in Table 1, the factor conditions are divided into primary factors and advanced factors. Primary factors include labor conditions, geographic conditions, natural resources, etc., which are innate factors; advanced factors refer to factors obtained through training or investment, such as personnel training, technology investment, and telecommunication networks. If a country puts its competitive advantage on primary factors, its competition is unstable. For example, labor-intensive industries developed through abundant resources and cheap labor cannot obtain international competitiveness. On the contrary, the industrial competitiveness that a country obtains through advanced factors factors is strong and lasting.

In this survey (Table 1), the phenomenon of lack of labor in enterprises is very serious. 93\% of the enterprises lack or very lack of employees; the situation of the lack of senior management personnel reflected in the survey is also relatively bad, with $82 \%$ of the enterprises are lacking or abnormally lacking;in the survey of the price increase of productive raw materials, it also reflects the gradual loss of resource endowment advantages that $98 \%$ of the enterprises report that the price of raw materials has increased significantly compared with the past [3]. It shows that the original resource endowment and labor advantage of the shoe industry clusters in coastal areas are gradually weakening.

5.2 Gradually Weakening in Resource Endowment and Labor Advantage of the Shoe Industry Clusters in Coastal Areas

First of all, land price has increased sharply. The per capita land area is lower than that of the national average. In addition, the real estate industry has overheated in recent years. Some companies have hoarded land and speculated on real estate, which has resulted in a large gap in industrial land, soaring land prices and higher land prices and forcing some companies to consider relocating to areas with preferential policies, labor resources, and land resources [4].

Secondly, the power supply is very tight. In the summer, there are often power cuts, forcing companies to use diesel for power generation, leading to higher production costs.

Thirdly, the continuous appreciation of the RMB has led to an increase in the cost of footwear export companies Most of the products of companies in the shoe industry cluster rely on export, and most of their target markets are the United States. The RMB continues to appreciate sharply, and there is a sign of acceleration, resulting in cost rising. If raw materials is imported, the impact will be small. Because the decrease of import cost and the decrease of export cost offset each other to resolve the impact of the RMB appreciation. In addition, China's export trade is far greater than import. In order to ease the trade surplus and reduce trade frictions, the government has taken the initiative to lower the export tax rebate rate, including clothing, footwear and headwear companies.

Finally, the comparative advantage of labor in the shoe industry cluster gradually weakens.

Multinational companies allocate production links to China's shoe industry clusters not only because of the advanced manufacturing technology, but also because of the cheap and sufficient labor cost. This cost mainly includes workers'salary, welfare, working environment, etc. At present, due to various reasons, this cost advantage

ISSN: 0010-8189

(C) CONVERTER 2020

www.converter-magazine.info 
is gradually weakening. The reason is that in recent years, China has attached great importance to the three rural issues, farmers' income has been greatly improved, and the initiative of going out to work has gradually decreased [5]. At the same time, there is a wave of laborers demanding higher salary, better living and working environment in coastal areas. Thus, labor in these areas is no longer cheap. This phenomenon will force labor-intensive enterprises to carry out industrial adjustment and transfer.

In short, due to the development of China's sporting goods industry clusters, the advantages of industrial agglomeration within the cluster have gradually emerged and strengthened, which not only reduces the transaction costs of enterprises in the cluster, but also leads to an increase in local cost factors and changes in the business cost structure. The game between the two will inevitably prompt enterprises in the cluster to carry out industrial upgrading and transfer.

\section{Countermeasures for the Upgrading of China's Sports Shoe Industry Clusters}

\subsection{Improving Innovation Ability and Cultivating Differentiated Competition}

Differentiation is an important way for an enterprise to gain a competitive advantage, that is to say, an enterprise establishes a unique product image and brand characteristics through different products, differentiates its products from others, and avoids price competition. The essential way to improve the product differentiation ability is to improve the innovation ability of the enterprise [6]. So how to obtain the innovation ability of enterprises in the cluster? Through analysis, there are roughly the following ways: First is to establish an innovation alliance through cooperation. Leading companies take the lead in product and technology research and development, and share the results. Through the sharing of research and development results, upstream and downstream companies that cooperate with leading companies will have significant improvement in the technical level and production efficiency. And the cooperation with the production of leading companies will improve the production efficiency of the entire group. Second is to achieve the diffusion of innovative knowledge through frequent exchanges. Due to the geographical relationship, they are relatively close to each other and have frequent contacts. They can quickly spread out innovative knowledge through informal and extensive contacts, and jointly seek brand innovation and technological innovation.

6.2 It's necessary to actively recruit talents to improve the human resources and management level of the footwear industry.

Enterprise competition and market competition are ultimately the competition of talents [7]. Therefore, it is necessary for the government to establish a good mechanism for introducing and cultivating talents to attract and retain outstanding talents for corporate innovation and product innovation, and adopt a variety of methods to motivate employees' innovation enthusiasm, maximize the potential of corporate employees, increase investment in scientific research, formulate and improve the incentive mechanism, encourage employees to carry out innovative activities, take innovation as the source of the core competition, and carry out product upgrading and enterprise upgrading.

6.3 Building a "Leading Enterprise" to Encourage Mergers and Reorganizations among Enterprises to Build a Cluster Industrial Chain

At present, many companies in China have financed through the capital market, and they have certain competitiveness in capital, brand and sales channels. And in accordance with the requirements of the modern enterprise system, a joint-stock limited liability company was established to realize the diversification of corporate property rights and become a competitive sports footwear "leading enterprise". The problem is that it is far from the world's top sports footwear brand enterprises in terms of output value, product volume, research and development, sales, logistics, after-sales service and brand awareness. Therefore, it is recommended that leading companies with a certain scale establish strategic alliances to carry out technical cooperation, product research $\&$

ISSN: 0010-8189

(C) CONVERTER 2020

www.converter-magazine.info 
development and logistics coordination, etc., to form a virtual "aircraft carrier" enterprise group to jointly fight against Nike, Adidas and other world-class sporting brand enterprises. While small and medium-sized footwear companies should rely on large-scale "aircraft carrier" footwear groups with products as a link to divide the industry, refine and strengthen each link of the industrial chain, and form a reasonable "large, medium and small" symbiosis industry group within the cluster to improve the level of product specialization, make the footwear cluster more specialized, large-scale and collaborative, effectively reduce production costs, enhance low-cost advantages, and improve the overall competitiveness of footwear clusters.

\subsection{Self-made Brands Entering the High-end Links of the Value Chain.}

Through professional development and mutual cooperation and division of labor, the enterprises in the cluster have passed the original capital stage. Companies have begun to develop towards product branding to cultivate differentiated innovation capabilities and achieve product functional upgrades. Therefore, leading companies should firstly create famous high-quality brands in the country, and then enter the international market with their own brands, embed in the global value chain, move toward the high-end links of the value chain, occupy the high added value of the product and realize the product functional upgrades. For example, build their own marketing network overseas. Anta enters the international mid-to-high-end footwear market through monopoly stores [8].By the first half of 2004, Anta had established more than 80 Anta monopoly stores overseas. Anta's overseas stores all achieved profitability that year, and the retail price of each pair of Anta sporting shoes was more than USD60. This mode is not only good for the development of foreign markets, but also easy for the company to control.

\subsection{Cooperating with International First-Tier Brand Enterprises to Achieve Value Chain Upgrading}

Strengthen the external connections of cluster enterprises, integrate into the global value chain with the capital, technology, brand, and sales channels of global purchasers, and cooperate with them to achieve a win-win goal. The specific approach is to use the desire of similar foreign companies to enter the Chinese market, form a strategic alliance with them, share domestic sales channels and use their foreign sales channels to promote our own brand products. For example, in 2003, Anta took advantage of its domestic marketing network to obtain a cooperation with the Italian brand manufacturer GEOX. According to the agreement between Anta and GEOX, all GEOX agents around the world must operate the Anta brand at the same time-not in the GEOX store, but to reopen an Anta store. While Anta is responsible for GEOX's brand promotion, network construction and product sales in China [9].

\subsection{Mergers and Acquisitions with Well-Known Foreign Brands to Rapidly Expand Foreign Sales Channels}

The acquisition of well-known foreign brands can gain the timeliness of building an international market and help domestic sporting goods companies to achieve the purpose pf quickly controlling foreign sales channels. For example, Fila has strong brand recognition and brand influence in high-end fashion sports markets such as tennis and golf. Anta has the strongest brand loyalty and management capabilities in the mass market, so both parties both parties will play a good role in promoting brand management and channel interoperability. On the other hand, Fila has a strong research \& development advantage in professional sport items such as tennis and golf. Anta has China's first sport science laboratory. With the improvement of scientific and technological research and development, Anta's products have moved from the domestic CBA to the international NBA. The two parties have broad room for cooperation in the field of scientific and technological research and development [10].

\section{Conclusion}

(1) China's sports shoe industry clusters must implement mergers and reorganizations, emphasize the division of labor and collaborative development of large, medium and small enterprises in production methods, improve the collaboration capabilities of the entire cluster, avoid excessive competition among enterprises, reduce wasteful investment in advertising resources, and increase operation cost, so as to optimize the allocation of resources and

ISSN: 0010-8189

(C) CONVERTER 2020 
improve market competition.

(2) China's sports shoe industry cluster should change the concept of competition from individual competition among enterprises to competition among product value chains, jointly bear product management risks, and strive to maximize the overall benefits of the product value chain.

(3) China's sports shoe industry clusters must integrate and cross each other when using the three cluster upgrading methods including technological process upgrading, product upgrading and product function upgrading. Sometimes they can be converted to each other without fixed upgrade mode. The upgrading of clusters should aim at cultivating innovation ability, enhancing competitive advantages, maximizing strengths and avoiding weaknesses, and creating differentiated competition.

\section{References}

[1] L.Q. Chen, “Research Overview on Global Value Chain Theory," http://www.chinavalue.net/Article/Archive/2009/5/7/174396.html.

[2] J. Zhang, "Upgrading of Ningbo Garment Industry Cluster Based on Global Value Chain," Academic Dissertation of Hunan University, 2007

[3] S.J. Zhang, "Industrial Transfer and Regional Coordinated Development of the Global Value Chain Mode," Finance and Economics, no. 2, pp. 42-45, 2009.

[4] T. Lin, "Current Situation Analysis and Development Suggestion of Shoemaking Industry in Jinjiang," financial Practice, Issue, 2008

[5] Z. Bai, "Investigation and Research on the Upgrading of Sporting Goods in China under the Global Value Chain,” Journal of Wuhan Institute of Physical Education, no. 7, pp. 18-20, 2010.

[6] H.W. Li, Z. Bai, "Research on the Opportunities and Challenges of China's Sporting Goods Companies Facing the ASEAN Free Trade Area," Journal of Beijing Sport University, no. 11, pp. 12-14, 2010.

[7] H. Zhang, "Current Situation and Countermeasures of Industrial Clusters in Central China," Journal of Henan University, no. 12, pp. 20-22, 2008.

[8] P. Tang, "Current Situation and Countermeasures of Industrial Clusters in China," Journal of Henan University, no. 12, pp.18-20, 2009.

[9] Y.T. Zhou, Z. Bai etc., "Research on the Upgrading of Sporting Goods in China under the Global Value Chain," Journal of Beijing Institute of Physical Education, Issue 9, 2009

[10] J.Y. Wang, "Anta Acquiring the Trademark Rights of Fila China," http://www.ijjnews.com/channel/2009814/n850812880_1.html. 